RESEARCH ARTICLE

\title{
What Do We Know about Psi? The First Decade of Remote-Viewing Research and Operations at Stanford Research Institute
}

\author{
RUSSELL TARG \\ Submitted September 18, 2019; Accepted September 29, 2019; Published December 30, 2019 \\ DOI: https://doi.org/10.31275/2019/1669 \\ Copyright: Creative Commons CC-BY-NC
}

\begin{abstract}
Beginning in 1972, three physicists at Stanford Research Institute (now known as SRI International)—Harold Puthoff, Edwin May, and Russell Targ-initiated free-response, remote-viewing experiments with psi-gifted participants. The percipients were asked to describe their mental images with regard to some person or event distant in space and time. Many of our experimental series were statistically significant at four standard deviations from chance expectation, with effect sizes greater than 0.6. From these highly efficient experiments, we concluded that the accuracy and reliability of remote viewing is independent of distance up to $10,000 \mathrm{~km}$, and of time up to several days into the future. Psi ability clearly violates our ordinary ideas of causality, since future events are seen to be the cause or trigger for experiences at an earlier time. We also learned that feedback to the viewer is helpful, but it is not necessary. Remote viewing is a nonanalytic ability; describing a distant shape, form, or location on the planet is easier than guessing a number from 1 to 10 . The purpose of this paper is to correct the misconception that psi is weak and unreliable. On the contrary, in our laboratory experiments and classified operational tasks, psi was found to be surprisingly reliable and useful.
\end{abstract}

Keywords: SRI—remote viewing—psi ability—psi results

\section{A Personal Note}

In 1958, I started my career in the budding area of laser research. My very poor vision compelled me to leave my atomic physics research assistantship with C. S. Wu at Columbia University, and shift to research in optics and then to psi research. At Columbia all the professors were much too smart to use textbooks. In those days, everything was taught from the mind of the professor directly to the blackboard in the lecture theater. My very poor 
eyesight made this form of classroom learning quite difficult for me. As an undergraduate in physics with a minor in psychology, I loved Carl Rogers who taught his students to be kind to their patients and treat them with "unconditional positive regard," not like lab rats. I became a student of parapsychology ever since the day that my fellow student in high school biology, Robert Rosenthal (now a distinguished professor), introduced the class to the Zener cards that were used in Rhine's laboratory to test for psi. I made a beeline for the American Society for Psychical Research (ASPR) just off Central Park West in New York City. For me, the rest is history. A decade of Indian Kundalini meditation practice at the New York Theosophical Society was also an important part of my life.

By the time I was in college at the age of sixteen, I was an amateur magician doing mental magic on stage for small events. I found that I could occasionally supplement my act with useful bits of visual information that would appear in my awareness. These often were appropriate for the person whose mind I was pretending to read. Since then, I have learned from famous magicians such as the Amazing Kreskin and Milbourne Christopher, that useful bits of stray information often come to them on stage anomalously.

By 1965, I had built an electronic ESP teaching machine which was instrumental in getting the first psi research contract at Stanford Research Institute (SRI). I had been exploring the possibility of such a program at a NASA conference on Speculative Technology. Wernher von Braun, the famous aerospace engineer, tried his hand at the ESP machine and was exceptionally successful. He recommended to James Fletcher, the director of NASA, that they could help support a program to "teach astronauts how to mentally become in touch with the spacecraft.' This led to a meeting with Hal Puthoff, astronaut Edgar Mitchell, Charles Anderson (President of SRI), and me in 1972. Mitchell confirmed that NASA would support research with an ESP teaching machine, and we all agreed to keep the project on a low profile. This was the inception of psi research at SRI that eventually culminated in 1995 at Science Applications International Corporation (SAIC). This project is now widely known as the Stargate Project.

After spending ten years at SRI on the psi research program, in July 1982 I decided to pursue my earlier laser work at Lockheed Missiles and Space Company. However, my interest in psi persisted. One of the questions that psi researchers are always faced with is 'if psi is real why can't you make money from it on the stock market?' In 1982 I created Delphi Associates with an investor and an experienced psychic to forecast changes in the silver commodity market. All nine forecasts were correct, and we made $\$ 120,000$. The event was reported in The Wall Street Journal (Larson, 1984; Harary \& Targ, 1985). 


\section{Remote Viewing at SRI}

Remote viewing is a methodological approach for the investigation and application of precognition and real-time psi. Psi is an inherent ability that enables us to describe and experience non-inferential objects and events in the distance and in the future. While some may not have this inherent ability, others may have it at varying degrees of proficiency-from a oncein-a-lifetime experience to giftedness that enables psi on demand.

This ability is not a "new age" discovery. Psi experiences are described in detail by the Hindu sage Patañjali in about the fourth century BCE in the Yoga Sütras (Taimni \& Patañjali, 2010). The eight-stage yoga practice consists of restraints, disciplines, physical posture, breath control, withdrawal of the senses, concentration, meditation, and samādhi, a state of super-consciousness. According to Patañjali, siddhis or supernormal powers are obtained by samyama, or perfect meditation, leading to clarity of insight. This enables the practitioner to gain knowledge of the past, the distant, and the future; diagnose illnesses; and heal the sick. In Part III of the Yoga Sūtras (Powers), Patañjali describes a wide variety of the siddhis (psi abilities). Siddhis are also described in the Buddhist treatise The Flower Ornament Scripture (Avatamsaka Sūtra, about the first century CE), that describe many of miraculous aspects of Buddhist life (Cleary, 1993). This 1600-page treatise also describes the ten kinds of super knowledge that enlightened beings have, including knowledge of other's minds (telepathy), knowledge of the celestial eye (clairvoyance), the spiritual faculty of knowing past lives, and the power of knowing the future (precognition). These revered scriptures expect their practitioners to follow the instructions, and in the process attain highly significant paranormal abilities. However, the attainment of psi abilities is not the goal of meditation. Focusing on the experience of siddhis is considered an impediment to attaining the ultimate goal of yoga - enlightenment and self-realization. But there is no doubt that these teachers consider the abilities to be available, though ego attachment is a stumbling block in the path of enlightenment.

We undertook several basic research experiments in the first decade at SRI, including psychokinesis, development of the remote-viewing method, remote viewing in an electronically shielded room (no degradation in psi performance), methods for identification and selection of psi-gifted persons (remote viewing tests were found to be best predictors of psi ability), training psi-gifted persons to utilize the remote-viewing methods, and applications of remote viewing to problems of national security. A 1973-1988 metaanalysis of the SRI data concluded that: 
Remote viewing (RV) can provide useful intelligence information.

Laboratory and operational remote viewing show the greatest potential for practical applications.

Experienced viewers are significantly better than the general population.

Remote-viewing ability does not degrade over time.

At this time, there is no quantitative evidence to support a training hypothesis, apart from basic instructions.

Natural scenes are significantly better than symbols as targets for remote viewing.

Remote-viewing quality is independent of target distance, size, or time, up to a few weeks.

(May, Utts, Trask, Luke, Frivold, \& Humphrey, 1989, p. 495)

It has been my great privilege to have worked with the greatest psychics of this era, learning from them, and contributing to the advancement of psi research. In this article, I briefly narrate my experiences with Ingo Swann, Pat Price, Hella Hammid, and Joe McMoneagle.

\section{Ingo Swann}

Following the initial funding from NASA, Ingo Swann, the noted New York visionary artist, was invited to SRI to demonstrate his psi abilities that were earlier investigated by Gertrude Schmeidler at the American Society for Psychical Research. Swann was not satisfied with the simplistic laboratory experiments to demonstrate his psi skills, as he felt these methods were a "trivialization of his abilities." Since he could focus his awareness "anywhere in the galaxy," his complaint was why were we asking him to describe stuff in the next room? He proposed that Hal and I go and stand anywhere in Palo Alto, a half hour's drive away from SRI, and he would make a drawing of where we were located. In one instance, we randomly chose Palo Alto City Hall, which he described as a "quad or quadrangle, a fountain with no water, and interlocking circles on the pavement." All correct. This launched us on a protocol of remote viewing of geographic locations, with an outbound person acting as a beacon, and the remote viewer in the laboratory with the interviewer. For the next decade, that interviewer was generally me, sitting in a darkened room, trying to gently help a viewer describe his mental pictures pertaining to where someone or something was located somewhere in the world. My job as an interviewer was to help people get out of their own way and not overthink the task.

Ingo was a lifelong, natural psychic who had no need for nor interest in an interviewer; for him, his description of us standing at City Hall was garden-variety remote viewing. After this early series of trials over several months, we were ready for a far more rigorous series of tests. Following the instructions of Swann, in the first formal experimental series we did at 
SRI, the viewer and I (as monitor) were sequestered in a shielded room, and Hal was the outbound experimenter to one of 60 randomly selected sites in the San Francisco Bay Area. Since I don't drive, I was the interviewer for most of the SRI remote-viewing experiments during the first decade. The protocol can be found in Puthoff, Targ, and May (1979).

In early 1973, our CIA contract monitor, Kit Green, sent us coordinates that we could use for our first formal test. Ingo was pleased with this targeting method as he had been pitching for the challenge of this approach. In May 1973, Ingo worked on the first set of coordinates provided, without any accompanying maps, giving an immediate response to the target coordinates. From Menlo Park, California, at SRI, Ingo provided the response of the West Virginia site (Figure 1). As we, at SRI, were all blind to these targets, the analysis of these responses was done by the clients. While the details of the analysis were not given to us, we were informed that in each of the experiments "the data exceed any possible bounds of coincidental correlation, and exceed any possible bounds of acquisition by known means." The target described by Swann was a top-secret (crypto) NSA microwave listening post. It has also been reported that some of the data possibly constitute "noise" in the signal, "but it has been difficult to negate totally any information given by the subjects" (Puthoff \& Targ, 1973, p. 72). The great psychic policeman Pat Price, whom we describe later, also penetrated the site to read top-secret code words in an underground safe. The details Price provided far exceeded what we and the clients anticipated or thought possible. Details of this can be found in The Reality of ESP (Targ, 2012, p. 49). As the target was not under the control of anyone at SRI, this exciting remote viewing generated a lot of interest and possibly concern in the intelligence community, and provided a great financial boost to our program. There was quite a dustup, with the NSA very angry with the CIA for targeting California psychics on their secret facility. No one was amused, except perhaps the psychics.

In other tasks, Ingo described, using only their geographic coordinates, targets such as an active volcano in Iceland and a French island called Kerguelen in the South Indian Ocean (see Figure 2). At this time, only the CIA had maps that could corroborate the exact location of the airport that Ingo drew on the tiny island, shown as parallel lines in the upper right part of the drawing.

Ingo had come to SRI with a well-annotated copy of René Warcollier's 1948 seminal book on telepathy called Mind to Mind (Warcollier, 1948). Swann later wrote an Introduction to the 2001 edition of that book, which I co-published with Hampton Roads, in my Studies in Consciousness series. In his Introduction, Ingo identified three ideas of Warcollier that had not yet 
574

Russell Marg

town

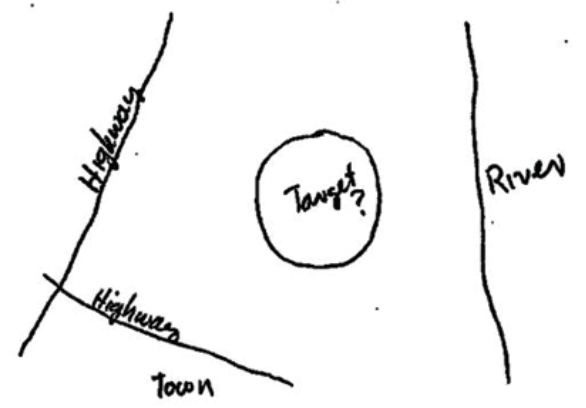

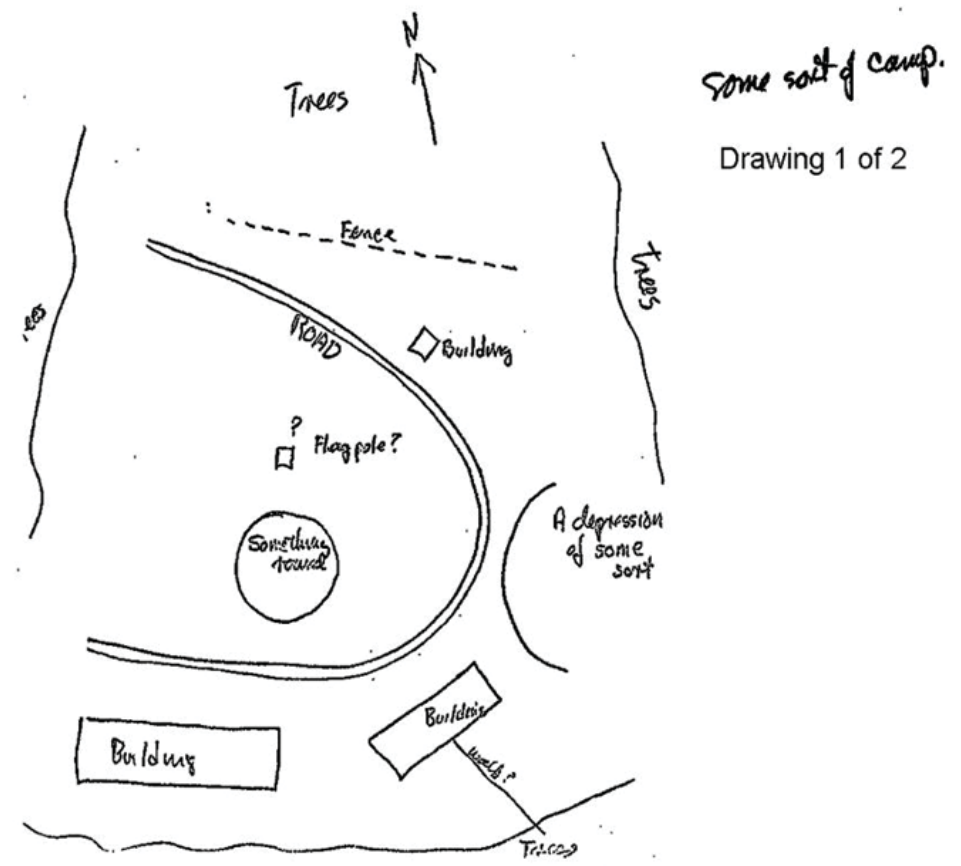

Drawing 2 of 2

Figure 1. lIngo Swann's Map \#1 and \#2, West Virginia Site. 

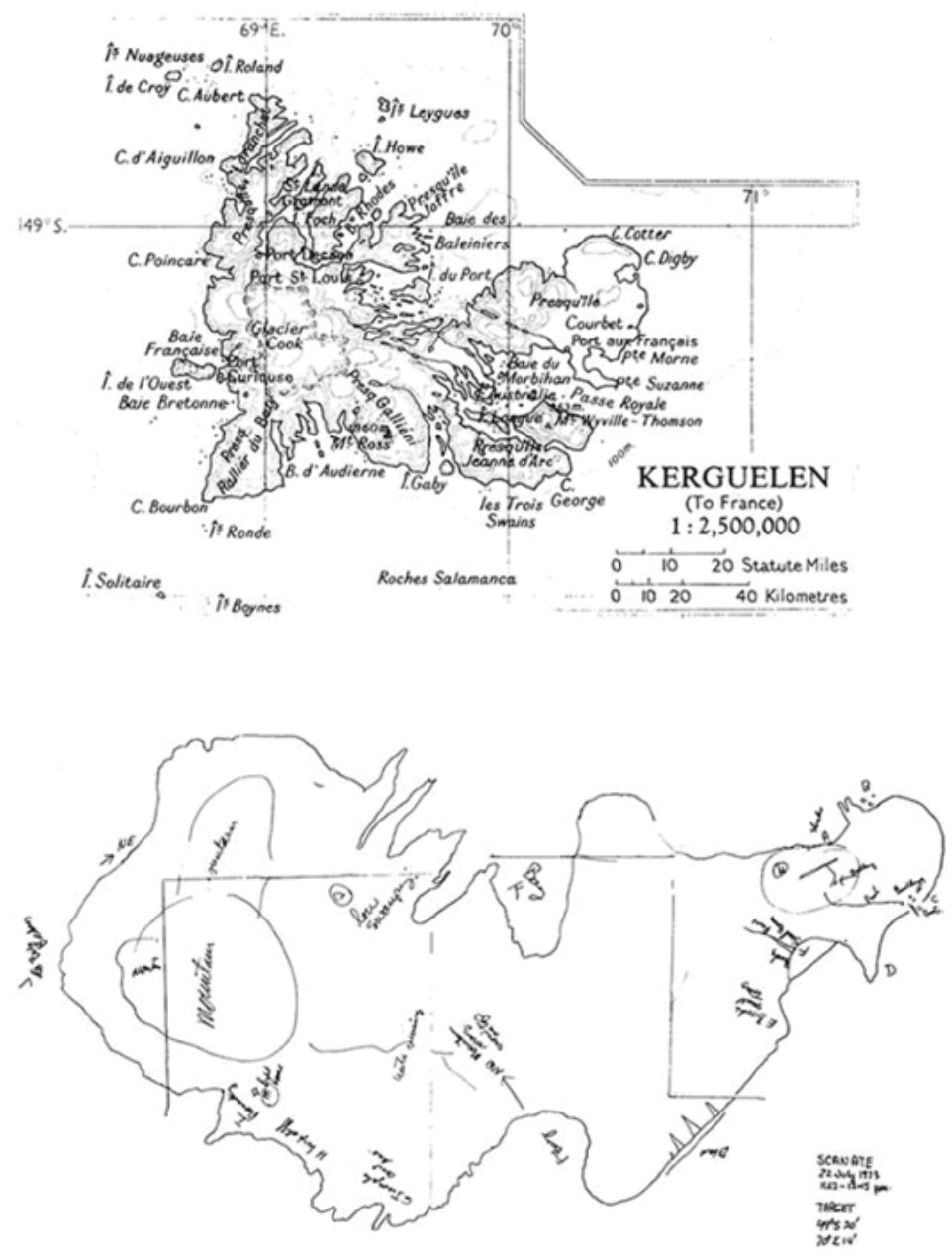

Figure 2. Kerguelen Island map and Swann's remote viewing sketch.

come into clear existence at the time of the 1948 edition. These concepts are models of mind, information transfer, and signal-to-noise ratio.

Models of Mind. From my conversations with Ingo, I am assuming that by "models of mind" he is referring to the bicameral nature of the brain, based on Julian Jaynes' work (Jaynes, 1976). One cerebral hemisphere is predominately associated with analytic function such as naming, while the other hemisphere works more holistically, as in drawing. I always ask a viewer to tell me, "What are you experiencing? What is the shape, or form? 
Tell me about the surprising image that appears in your awareness." This approach has been very successful. Asking the viewer "where do you think Hal is located" always fails. It is easier to visualize someone's location anywhere in the world, than to guess a number from 1 to 10, an ESP card, or a playing card. This is because naming the card is an analytic task and does not correspond to how psi works. This is not a new idea. It is found in the eighth century Tibetan Buddhist text by the great dharma master Padmasambhava, also known as Guru Rinpoche; Self-Liberation through Seeing with Naked Awareness is a translation of this text (Karma-glin-pa \& Reynolds, 2010). The idea here is that our nature is timeless awareness, and to move awareness into the timeless realm, one "must give up all desire for naming and grasping. Naming and grasping is the enemy of timeless awareness." You might say that the remote-viewing monitor/interviewer plays the part of the viewer's analytical hemisphere.

Information Transfer. As an artist, Ingo believed in the wisdom of the hand. He always asked a viewer to begin any session by relaxing his hand and making a little sketch, formless or not. He felt that these "glyphs" were the first and truest link with the image being processed by the psychic mind. Warcollier's book is filled with these little glyphs. I think drawings are very important. Since I am a good visualizer and not an artist, my first question as a monitor to a viewer almost always is, "Tell me what shows up surprising in your awareness. Good. Now draw that." I give them a piece of paper and a marker to concretize their visual imagery. In my experience, many people feel hesitant in trying to draw something that doesn't make any sense, but a good session monitor can encourage a person to put his imagery on paper either as drawings or words. I am not teaching remote viewing. I am giving people permission to use an ability they already have.

Signal-to-Noise Ratio. Ingo's focus was always on helping the viewer to separate "the psychic signal from the mental noise." While we don't know a lot about the psychic signal, we do have a good understanding of mental noise, which Ingo termed as analytical overlay (AOL), a very important concept. AOL is naming, guessing, grasping, memory, analysis, and imagination that interfere with the expression of psi-enabled information. Anything the viewer does in the way of processing his images introduces noise. This is why targets such as Zener cards and playing cards are psidestructive targets. In the forced-choice, card-guessing paradigm, the signalto-noise ratio is a huge problem, since you already have a perfect, crystalclear memory of all the cards. In the free-response approach, the diaphanous psi image does not have to compete with memory and imagination. 
In the free-response, remote-viewing tasks, an interviewer/monitor can be very helpful in guiding a viewer away from guessing targets. An interviewer can also become sensitive to the tone of voice that a viewer expresses during a remote-viewing session. Since the interviewer is blind to the target and the target pool, he has no information to contribute, and hence can say whatever he thinks might be helpful to encourage the viewer to elaborate on his response; even suggesting that he look into awareness for his future feedback. And above all, never lie to your subjects.

Precognitive dreams also are subject to mental noise, the same as ordinary remote viewing. But we can learn, and must learn, to recognize a true precognitive dream by its freedom from the previous day's residue, no anxiety about possible future events, or wish fulfillment of desired future events. While these three are the basis of most ordinary, non-precognitive dreams, future-oriented dreams are recognizable by their frequent bizarre content, or unusual crystal clarity. This separation is very important if precognitive dreams are to be trusted and put to work. For example, if you have an anxiety dream about failing a math test for which you have not studied, we would not call that precognitive. It's just what you would expect. But one can become skillful in discerning whether a dream is ordinary or is indeed precognitive. Although I personally have not found it necessary, maintaining a dream diary can be of great help.

In April 1973, we finally received our NASA contract to test my ESP teaching machine (Targ, Cole, \& Puthoff, 1974). This ESP Trainer is now available as a free application from the Apple App store. It is a four-choice, random-number-generator device that chooses the targets; it has a PASS button, to avoid guessing. Our contract monitor, George Pezdirtz, was a distinguished NASA chemist. He was an early associate for our team in getting governmental support for our program. As we sat with Ingo in my office in early April 1973, George mentioned that NASA was about to launch the Pioneer 11 spacecraft to Jupiter. Could Ingo take a look at Jupiter now, and tell us if there was anything especially interesting that the mission might find? Ingo took a puff on his cigar and grabbed my ruled note pad and said "yes, I see a ring around the planet." George said to Ingo, "You must be thinking of Saturn." Ingo replied in his inimitable style that he had been looking at the solar system his entire life, and that he knows the difference between Jupiter and Saturn. He said that "Jupiter has mainly one fat ring. And you will see it when you get there." The following year, NASA sent back photos greatly resembling Ingo's instant drawings of the ring 365 million miles away (see Figure 3). 

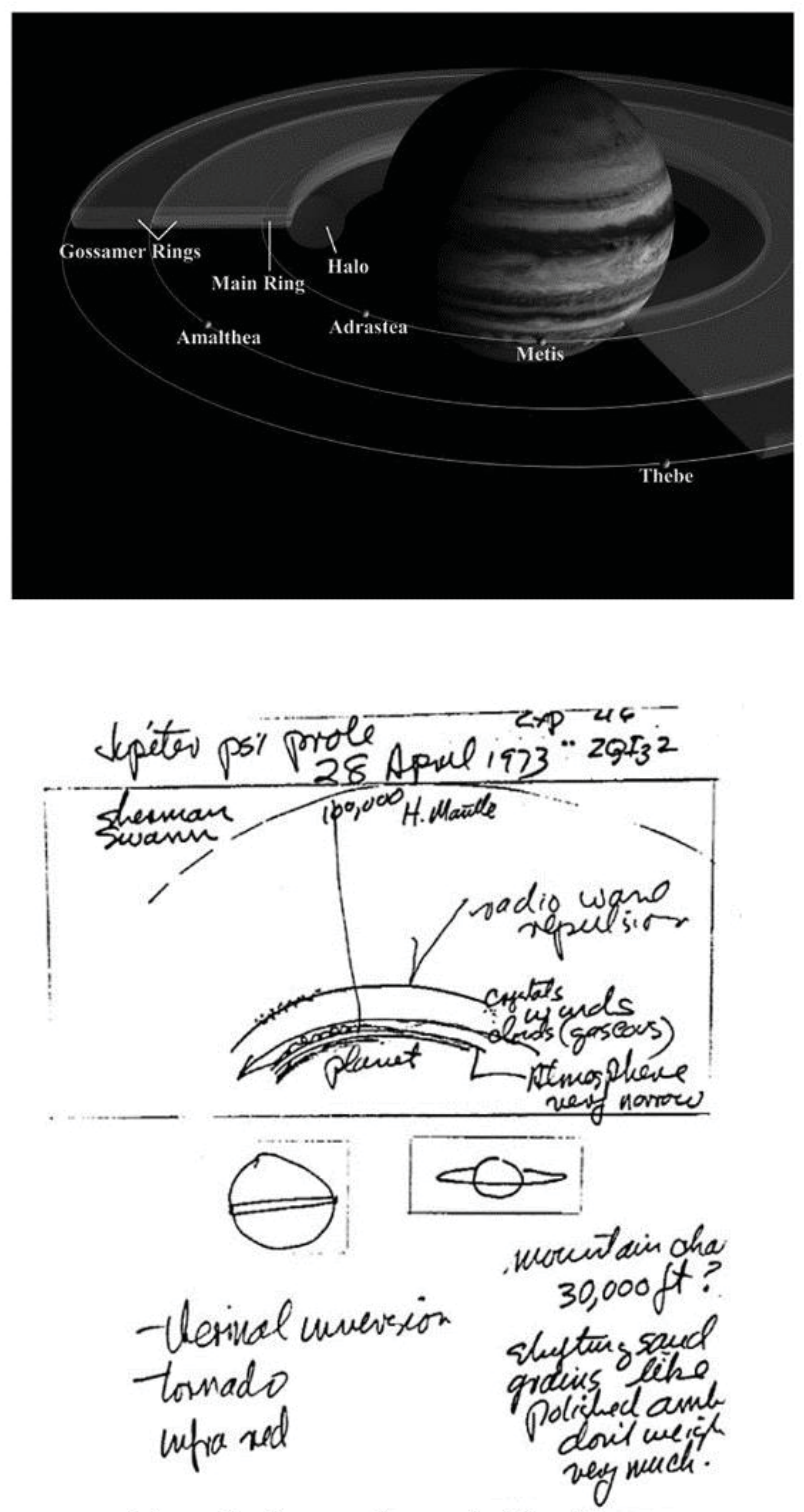

The subject incorrectly recorded the date. The date was 27 April 1973

Figure 3. NASA illustration of Jupiter's rings, and Swann's remote viewing sketch of Jupiter's rings. 


\section{Pat Price}

Pat Price was a retired police commissioner from the city of Burbank, California. He told us that he had heard of our ESP research at SRI, and that he would like to help us. I have no idea where he heard about our classified program. Pat was an amiable, mid-fifties, broad-shouldered Irishman, liked by everyone. In our first remote-viewing trial, Price and I sat in a small, shielded room with cups of coffee and a lined pad on which to draw or write notes. After allowing half an hour travel time, I announced that Hal and Kit Green, our contract monitor from the CIA, had reached their destination. Price said, 'I don't see anything.' Since this was my first remote-viewing trial with him, I found his announcement alarming. But I was familiar with the feeling of the remote-viewing experience from my own explorations. So I had no hesitation telling Price, "That's OK. Just follow Hal's green car as it leaves the SRI parking lot and tell me what you see." He said, "I see them heading south. They are arriving at some sort of large water purification plant.... There is a circular pool about 80 feet in diameter and a rectangular pool about 75 by 100 . And there are two very tall water storage tanks. That's what I get." The target was a public swimming pool complex in Rinconada Park about five miles south of SRI. The dimensions of the two pools that he described were correct. While there were no water tanks presently at the site, 75 years ago there used to be water tanks in the exact spot Price had indicated. Further, at an earlier time, the site was indeed a water purification plant. We learned those two facts ten years later. Figure 4 illustrates the existing pools, and the water towers from an earlier time.

Our plan called for accomplishing a total of nine trials with Pat, and with $\mathrm{Hal}$ as the outbound experimenter to a randomly selected site within half an hour's drive from SRI. We accomplished the nine trials with about two or three sessions a week. In double-blind, rank-order matching, the session judge was able to correctly match seven of the nine trials as firstplace matches, with respect to where the outbound experimenter had been. There are 60 targets in the pool. The judging is against the nine targets used in a $9 \times 9$ matrix. The judge was Arthur Hastings, then a linguistics professor at Stanford University.

The statistical odds of such success is approximately 1 -in-100,000. Another way to gain perspective on this series would be to realize that if $\mathrm{Hal}$ had been kidnapped on nine occasions, Pat would have found him the first place he remote-viewed in seven of the nine times. No correlation between distance and accuracy was found. In one trial, our division director wanted to assure security and hence drove himself and Hal to his own randomly chosen site. Pat and I were unaware of this change in protocol. Shortly after 


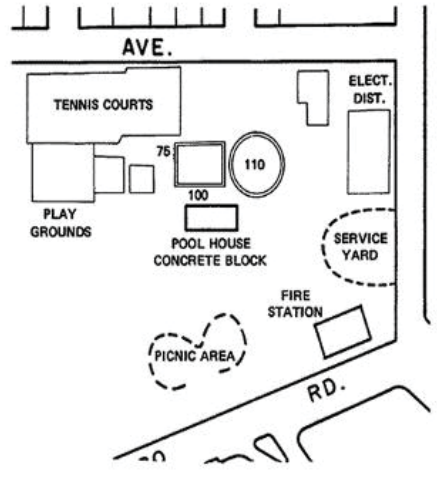

(a) City Map of Target Location

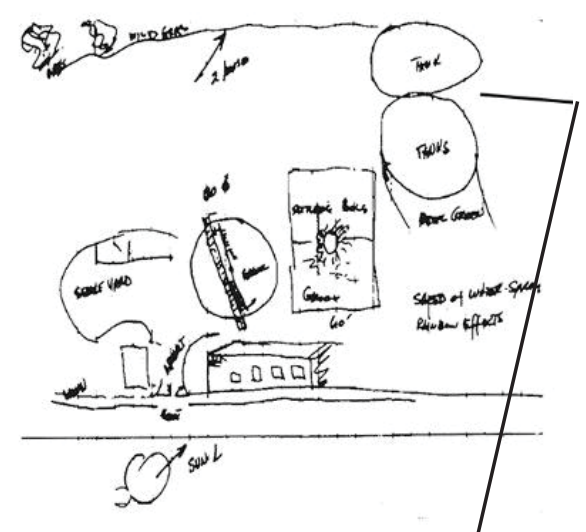

(b) Drawing by Subject S1

Figure 4. Map of public swimming-pool complex, remote-viewing drawing, and an archive photo of the towers.

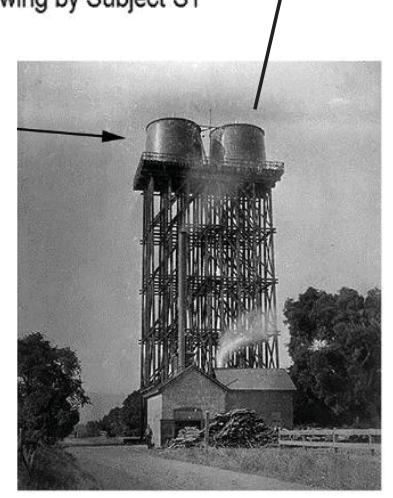

the travelers left, Pat said, "why don't I just tell you right now where they are going, and we can go and get our coffee." This turned out to be one of his most accurate descriptions. It was a boat dock and restaurant complex 10 miles north of SRI. After our Nature paper (Targ \& Puthoff, 1974) was published, there was a criticism of our judging protocol, based on the idea that some of the transcripts had internal clues, from the subject, as to the order of the trials. We asked Professor Charles Tart, at the University of California, Davis, to have the trials re-judged in his laboratory. His judge came up with exactly the same results as Professor Hastings did.

Kidnapping of Patty Hearst. In January 1974, Patricia Hearst, the heiress to the Hearst fortune, was kidnapped from her Berkeley home. The next day, local police called SRI to see if we could help. Hal, Pat Price, and I drove to the Berkeley police station to see what Pat could do. The police detective told Pat, "“Boy do we have a lot of questions to ask you!" Pat said, "Let me show you how we do this. Give me your mug book." The detective 
brought out a large, loose-leaf binder and laid it on a large oak table. We all crowded around Pat as he turned the pages, each with six square photos. After perhaps a dozen pages, Pat put his finger on the face of a man and read out loud "Donald Defreeze, he's the ring leader." The detective said "We know who he is. He walked away from a minimum security jail last year." A week later, Defreeze identified himself as the leader of the Symbionese Liberation Army, an American far-left militia group. In her autobiography, Every Secret Thing, Patty Hearst states that they knew psychics were looking for them (Hearst, 1982). She was captured September 19, 1975, by the FBI, in a San Francisco apartment.

Giant Sphere of Semipalatinsk. In June 1974, there was Pat Price's final event at SRI, a few months before his death. He described a Soviet weapons factory in Siberia. Using targets in Siberia overcomes the "memorized-the-globe hypothesis," which we sometimes heard from skeptics. Price and I were given geographical coordinates of a Russian R\&D facility. Price began by saying, "I am lying on top of a building, and the sun feels good. There is a giant gantry crane rolling back above my body. I need to draw this." And he made what turned out to be an extremely detailed drawing of an eight-wheeled gantry crane, with a little man half the height of a wheel. It was a shockingly accurate match with the secret drawing that the CIA brought to show us after the session. Ken Kress, the contracting office's technical representative, then asked Pat to describe what were they doing in the building underneath the crane. Price and I went back to our little room to continue the session, and Pat began to describe the construction of a giant steel sphere about 60 feet in diameter. He said, 'They're trying to weld it together out of steel gores (orange slices) but they are having problems because the steel is so thick." While at that time the CIA couldn't confirm anything about the sphere, Aviation Week published a story on May 2, 1977, describing satellite images of the Semipalatinsk site. Figure 5 shows the photo from Aviation Week illustrating Russian tanks made of gores, and Pat Price's drawing of the 60-foot gores making up the spheres. As stated in the Aviation Week article: "The building has been removed. The large steel segments were parts of a steel sphere estimated to be 18 meters ( 57 feet) in diameter. Enough gores for two complete spheres were constructed. The spheres are the first clue as to what is being done at the facility." In our film Third Eye Spies, Kit Green reiterates that they had no information about the spheres, even for us with our top-secret, SI-TK (Sensitive Intelligence Talent Keyhole) clearances.

Price was lauded for his excellent description of the spheres. It is interesting to note here that Price died the following year, before anyone in the West had information about the spheres. Thus, there was no feedback 

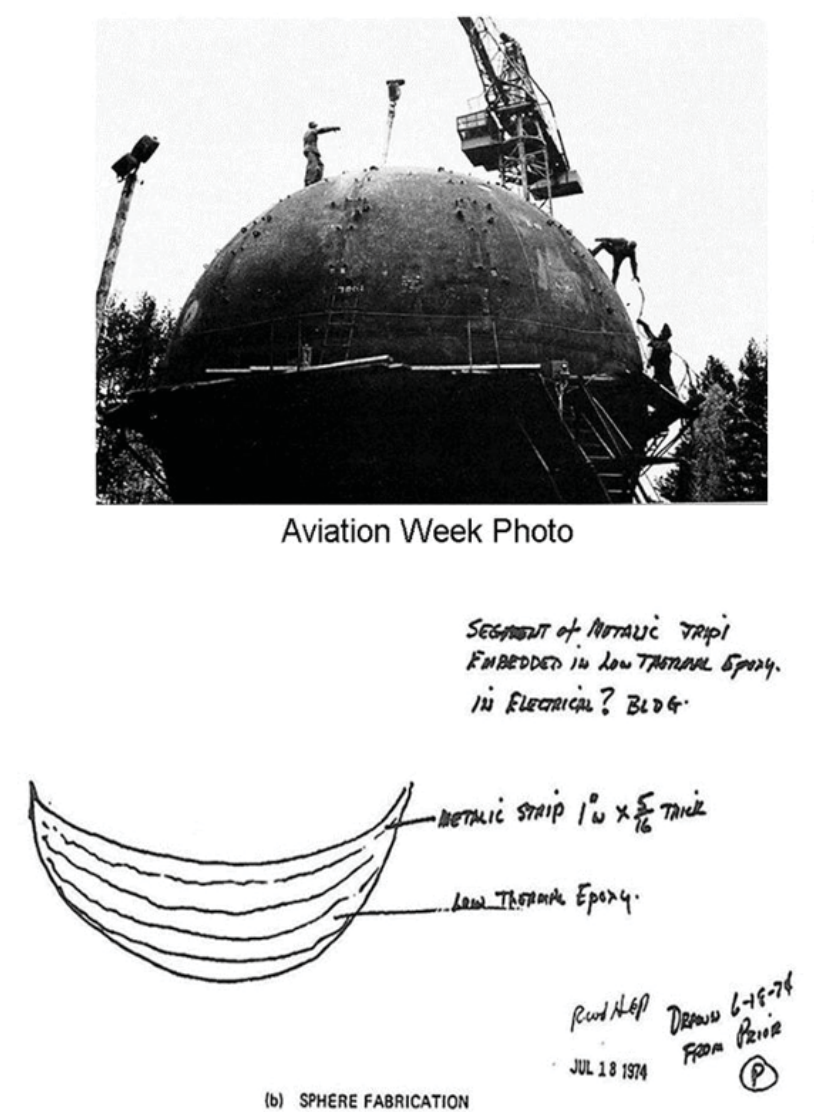

Figure 5. Semipalatinsk site: 1977 Aviation Week photo and 1974 Pat Price's drawing.

available to him after the session to serve as the source of psi information. In my view, this example settles the issue that feedback provided to the viewer is not necessary for remote viewing. Published laboratory experiments have also been done where feedback to the viewer had been carefully excluded, and psi was significantly evident (Schmeidler, 1964; Targ \& Tart, 1985; Targ, Targ, \& Lichtarge, 1985; May, Lantz, \& Piantineda, 1996/2014).

Hal and I worked together on the organization of all these projects. But just before we received the tasking for Semipalatinsk, Hal was invited to take a vacation trip to South America. This provided us an opportunity for 
a long-distance, remote-viewing series with Pat. Each day at noon, Pat and I would meet at our little shielded room in SRI, and he would describe his impressions of where Hal was in South America. He described for example, a church, a market, a harbor, and a volcano. Then on day five, he didn't show up. So, in the spirit that the show must go on, I decided to stand in for Pat. Since I had been facilitating this work for two years, I thought I would give it a try. At noon, I closed my eyes and took a couple of deep breaths. I saw an airport on an island, which I drew. I saw ocean at the end of the runway, sand and grass on the right, and an airport building on the left. I signed and dated my drawing. When Hal returned, he showed me his photos of the island airport he visited for a change of scene, or, as he said "to try and fool the viewer." My drawing closely matched what he saw at the airport (Figure 6). Shortly after that, we had an offer from a newspaper to fly their Florida-based airplane to the airport at San Andres to see if my drawing was as good as Hal claimed.

\section{Hella Hammid}

After two years of remote-viewing research at SRI and the publication of our first paper in Nature (Targ \& Puthoff, 1974), the CIA asked us to find a control subject who had no previous experience with psychic abilities. Kit Green, the CIA physician, wanted to determine how widely distributed psi ability was in the general population. Since Price and Swann were lifelong psi practitioners, and demonstrated prodigious abilities, could I find a control subject? I invited Hella Hammid - a family friend, renowned photographer, highly intelligent, with an enthusiastic sense of humor - to participate as a control subject. She had no prior experience of being psychic, and thought it would be very entertaining to be a part of a government ESP project. We carried out nine, formal, remote-viewing experiments with her, just as we had done with Price. We followed the outbound, remote-viewing protocol, with me as the monitor and $\mathrm{Hal}$ as the outbound experimenter. In doubleblind matching, a judge successfully matched five of her descriptions in first place and four in second place. In two of these sessions, there was a bridge in each of two targets, and two courtyards also appeared in her target pool; she described all of these quite accurately. But the judge was unable to determine which steel bridge drawing should be associated with the actual steel bridge. Figure 7 illustrates her first remote-viewing trial in the series with her drawing of a pedestrian overpass. She correctly characterized it as some kind of "trough, up in the air ... I see squares, within squares, within squares."

Her overall score was statistically significant at odds of 1 in $1,000,000$; the overpass was given only a second-place match by the judge, who 

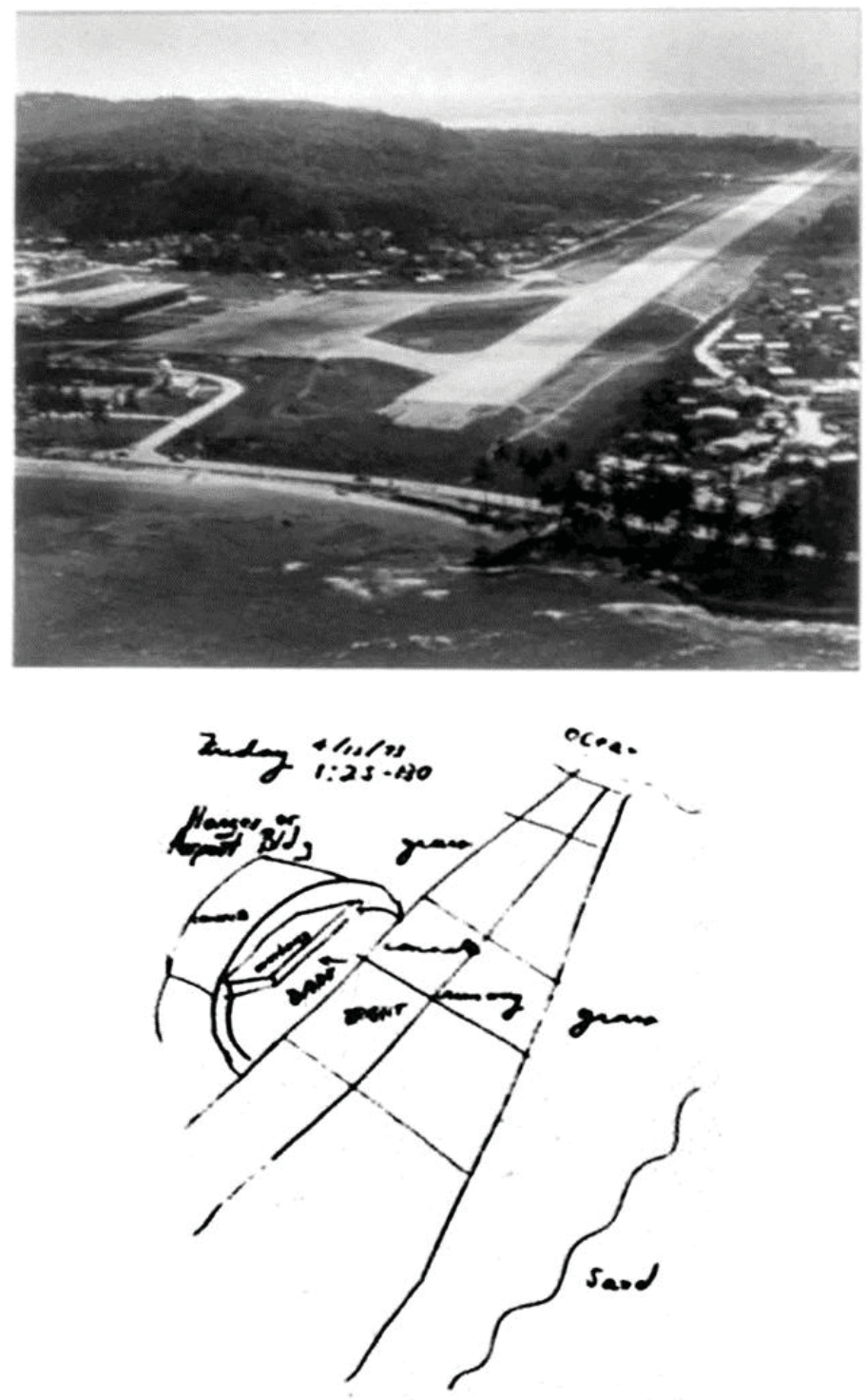

Figure 6. San Andrea's airport and Targ's remote-viewing drawing.

reasonably preferred a very similar railroad trestle. ${ }^{1}$ These formal studies were published in the Proceedings of the IEEE (Puthoff \& Targ, 1976). In trials such as we report here for Pat Price and Hella Hammid, the deviation from chance expectation is greater than $4 \sigma$. The effect size is calculated as 

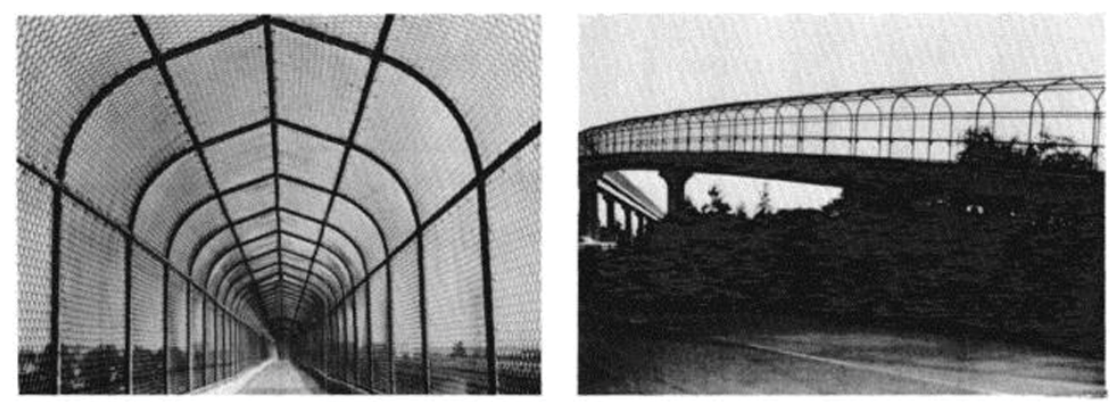

(1)
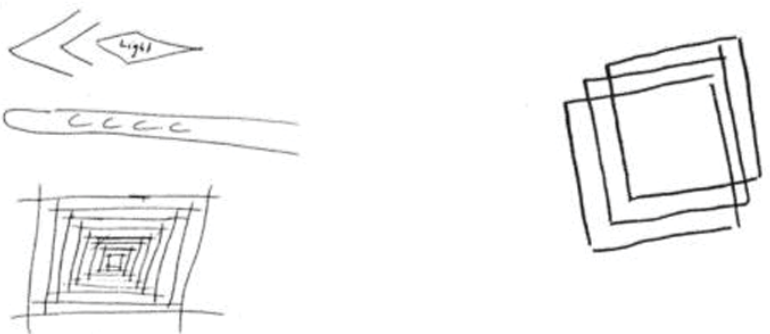

(a) Squares within squares

(b) Diagonal trough up in the air

Figure 7. Pedestrian overpass target, and Hella Hammid's drawing, described as "some kind of diagonal trough up in the air."

the $z$-score (the number of standard deviations from chance) divided by the square root of the number of trials. For these two series of nine trials each, the effect size is greater than unity. From my work on this program, I would say that all creative people are psychic, even scientists - they have just learned to keep quiet about it.

It wasn't lost on the CIA that our control subject appeared to be psigifted at a level of proficiency that matched that of Pat Price - our best psychic. Hella became a highly successful partner in our program for the next six years. She described objects near and far, big and small, all with great success. In one trial, we were concerned about the meaning of the result, when Hella made an exceptionally accurate drawing of an artist's representation of the Berkeley Bevatron particle accelerator which differed greatly from the aerial photograph of the actual structure. She had been shown both images for feedback. Figure 8 illustrates her drawing in response to the geographical coordinates of the Berkeley Bevatron building. Her sketch of the Bevatron "target area structure" was considered an anomalously accurate response to the geographic coordinates. It suggested to us that she might be responding to her feedback picture of the artist's drawing, rather 


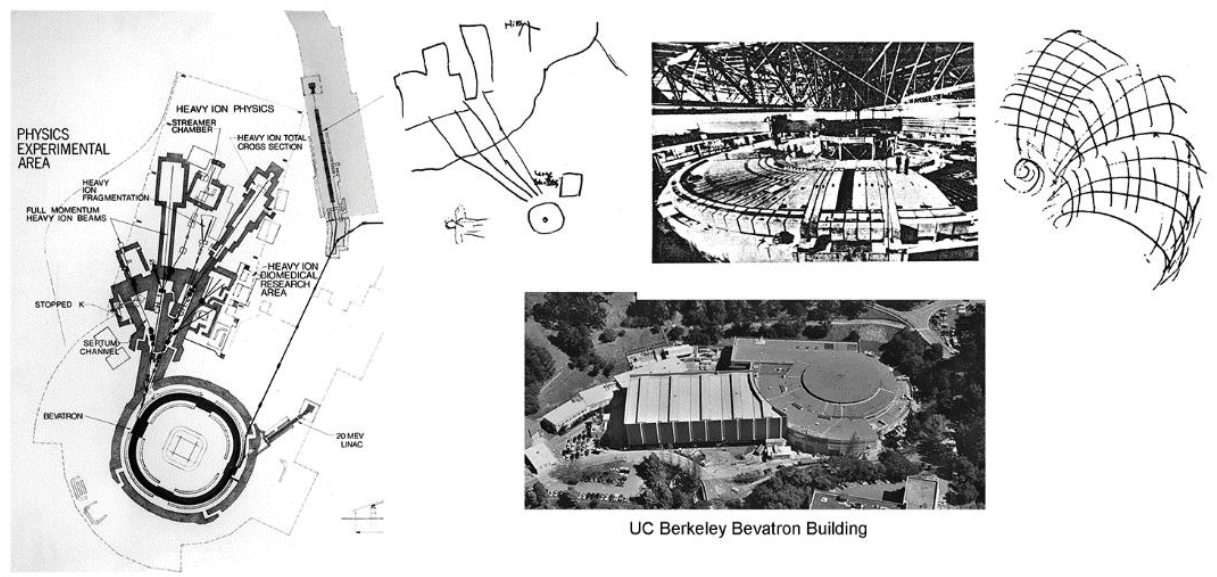

Figure 8. Berkeley Bevatron building, and sketch by Hella Hammid. She described these as "highly illuminated rays shooting out of a bellybutton type of roundness."

than to her remote viewing of the building itself (Figure 8, left).

As I have been saying, we consider remote viewing to be a nonlocal ability, that is, independent of space and time, because it is no more difficult to see into the far distance than it is to see across the street or to see into the future. In fact, Hella Hammid demonstrated perfect precognitive accuracy in her descriptions of four Bay Area targets, an hour before they were each chosen (Puthoff \& Targ, 1976).

\section{Joe McMoneagle and the Army Psychic Corps at Fort Meade, MD}

After six years of operational requests to SRI, from the CIA, and the Army Intelligence and Security Command (INSCOM), the Army asked us to train a group of intelligence officers on the East Coast. It was becoming cumbersome and embarrassing for them to have to come to SRI in California for tasking remote viewers to help them find a downed bomber or a kidnapped general. Hal and I went to Fort Meade in Maryland, and in a large meeting room interviewed 30 officers who were willing to risk their careers for an opportunity to learn remote viewing. Following the screening procedure, the selected six from this group, five men and one woman, came to SRI (Targ, 2014; Targ, Puthoff, Humphrey, \& May, 1980). We spent a week with each of them, instructing them on the remote-viewing protocol that we had been using for the past six years. We would conduct one trial each day and two on Friday. 

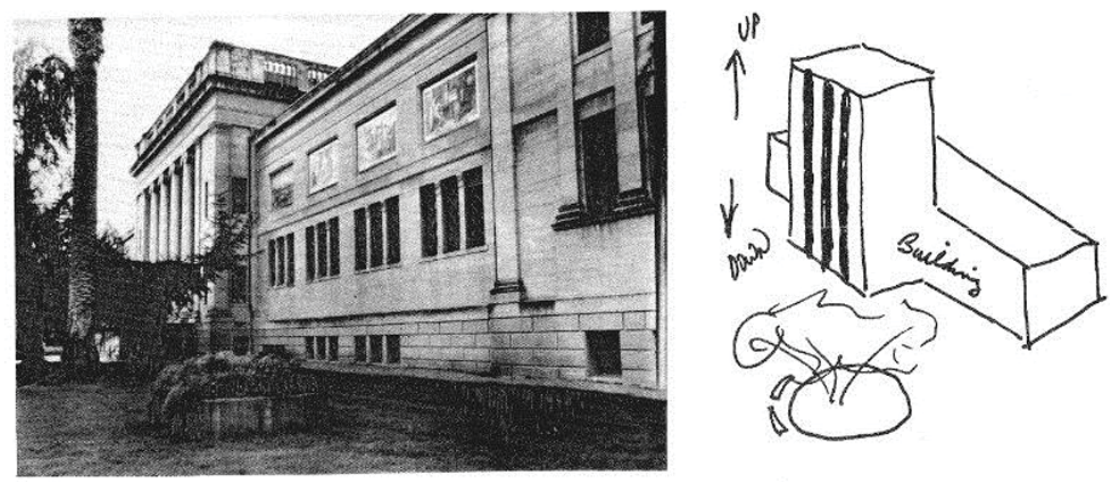

Figure 9. Stanford University Museum of Art building and Joe McMoneagle's remote-viewing drawing.

The first person I worked with was Joe McMoneagle, who was an Army chief warrant officer. In our first trial, Joe had several images show up in his awareness. One of these he drew in great detail. He made an almost architectural drawing of a building, which turned out to be the Stanford University Museum of Art (see Figure 9). The protocol for these sessions was to conduct a remote-viewing session first thing in the morning at SRI and then drive to the actual target site for feedback. The afternoons were free, as our practice has always been to have no more than one session per day with an individual viewer. Thus, we did six trials a week with each of the six visitors, for a total of thirty-six trials. The viewer's performance was evaluated individually. The results showed that four of our six army officers obtained statistically significant results, each less than 0.03 . Overall, in 36 trials, they achieved 19 first-place matches, where only six would be expected by chance. This is an outstanding result for a formal series with inexperienced viewers. This gave better than 1 -in-a-1,000,000 probability for the group as a whole. The effect size for the study was greater than 0.67.

We first presented our experimental data from Pat and Hella in 1975 at a Santa Barbara meeting of the Parapsychology Association. Many of the attending scientists, who grew up with card-guessing ESP tests, thought we must be either lying or stupid. We were reporting effects substantially greater than was customarily (or ever) seen in psi research. The Fort Meade study made it seem more real. At the same time, some replications began to come in from Professor Robert Jahn's laboratory at Princeton University. Up until the mid-1960s, the most-common psi experiments were of the card-guessing variety. These forced-choice trials typically had effect sizes of 0.02 (Honorton \& Ferrari, 1989). In the 1960s and early 1970s, the most 


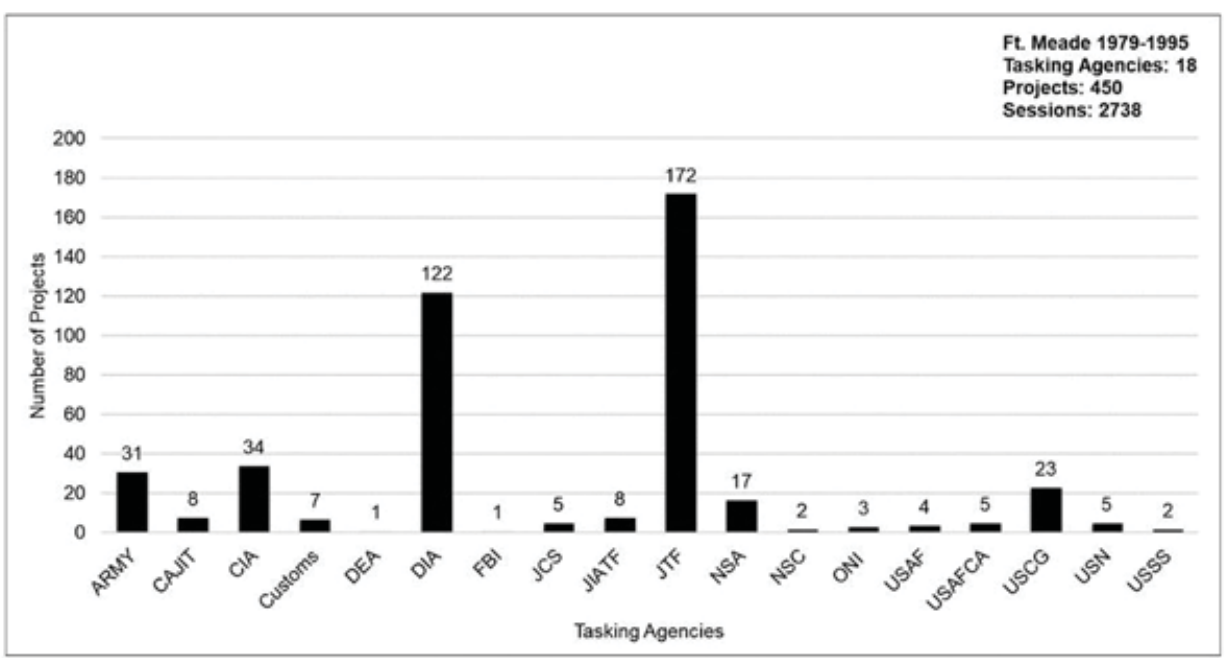

Figure 10. Client base for the Fort Meade RV-HUMINT program (1979-1995): Army-US Army Intelligence and Security Command; CAJIT-Central America Joint Intelligence Team; CIA-Central Intelligence Agency; Customs-US Customs; DEA-Drug Enforcement Agency; DIA-Defense Intelligence Agency; $\mathrm{FBI}$-Federal Bureau of Investigation; JCS-Joint Chiefs of Staff; JIATF-Joint Interagency Task Force; JTF-Joint Task Force; NSA-National Security Agency; NSC - National Security Council; ONIOffice of Naval Intelligence; USAF_-US Air Force; USAFCA—United States Army Foreign Counterintelligence Activity; USCG-US Coast Guard; USN_US Navy; USSS—US Secret Service (May \& Marwaha, 2019b, p. 18).

successful experiments were carried out in the free-response ganzfeld. This change made a great improvement in effect size, to 0.2 (Honorton et al., 1990).

Over time, the Fort Meade group comprised more than a dozen army and civilian viewers. They were in the business of doing operational remote viewing for fifteen years, from 1979 to 1995, for an assortment of US intelligence agencies including the CIA. The word on the street (Secretary of Defense Robert Gates on Nightline) was that the SRI-Fort Meade remoteviewing program never provided any useful information. That is simply not true. Figure 10 summarizes the client base for the remote-viewing, human intelligence program. In its 15 years of operation, the Fort Meade remoteviewing program received 450 requests for services from various US Government intelligence agencies. Despite the CIA's denial of the utility of remote viewing, they referred 34 missions to the remote-viewing human 
intelligence group at Fort Meade for their intelligence needs; with 122 from the Defense Intelligence Agency (DIA) and 172 from the Joint Task Force (JTF). This kind of repeat business strongly indicates that the customer was finding the information useful enough to keep coming back for more, thus lending support to the validity of psi and the utility of remote viewing. All the SRI-SAIC and government reports and reviews have now been published in four volumes as the Star Gate Archives by Edwin May, the former research director of the SRI-SAIC remote-viewing program (May \& Marwaha, 2018a, 2018b, 2019a, 2018b).

In several formal studies from the final decade of the Star Gate program at SRI-SAIC, Ed May found effect sizes of 0.4-0.5, mainly with talented and experienced remote viewers.

In 1978, a Soviet, Tpolev Tu-22 Backfire bomber went down in northern Africa. It was full of code books; and both the Russians and the CIA were eager to find it. However, since it crashed into the jungle, US satellite photography couldn't locate it. We were asked by our CIA customer to try to locate the plane by remote viewing. Both a talented SRI viewer and an experienced female remote viewer from the Wright-Patterson Air Force Base made contact with the plane. They both described the locale and drew a circle on a map. When the CIA landed a helicopter in that circle, the first thing they saw was a group of natives dragging pieces of the plane from the river to the village, just as the SRI viewer described. This whole event is narated by President Jimmy Carter in the opening scene of my 2018 documentary film Third Eye Spies.

\section{Final Thoughts}

One of the issues I have dealt with here is the question of whether feedback is necessary for psi functioning. The Fort Meade viewer often received no feedback about the target, or his success or failure, because he was not cleared at that level. Some researchers trying to make psi data compatible with quantum physics ideas have proposed that psi does not involve information transfer across space in present time, but that instead the remote viewer accomplishes her or his task by precognizing the sensory feedback about the target to be received later. Jacques Vallée, the wellknown researcher and writer, told us at a recent Parapsychology Association conference that "psi doesn't have to be a slave to physics. We have the data." What that means to me is that, although "entanglement" cannot be a vehicle for message-sending, the remote-viewing data offering evidence for psi from many labs over forty years is clearly nonlocal in space and time.

The great Buddhist dharma masters taught from their experience that 
separation of consciousness is an illusion. I think it is interesting to consider some of the ideas from Buddhism, because of their great density in Buddhist writing, and their close agreement with much that we see in the laboratory. There is no separation between the tasker and the viewer. In conclusion, I propose that in our interconnected nonlocal space-time, feedback about the target to a viewer is not necessary. If a viewer's consciousness has direct access to any point in space-time, we do not have to invoke any kind of separate retrocausation. The viewer doesn't have to ever physically see or experience the feedback. That is to say, he is not, in general, reading his own future mind as some, such as physicist Gerald Feinberg, conjectured. Many of these issues are discussed in Eric Wargo's excellent new book Time Loops (2018). Feedback to a new viewer is indeed helpful as a confidence-building measure; for an experienced viewer, the universe appears to provide all the connections to the target that is required to make psi possible. Erwin Schrödinger (1964), the physicist who perfected quantum mechanics, wrote, "I would not call entanglement one, but rather the, characteristic trait of quantum mechanics." He said that, "Consciousness is a singular of which there is no plural." And finally, since precognition and retrocausality are within the light cone, there is no contradiction with special relativity. That is, the ordinary causal ordering principle (COP), of physics, is not a limiting factor for consciousness.

\section{Note}

1 In later developments, the target pools were developed such that there were no target similarities in a target set. That is, a target set would contain, for instance, bridge, park, water tower, waterfall, pond. This ensured that there would be no confusion regarding which target was sketched by the remote viewer (see Humphrey, Trask, May, \& Thomson, 1986; May, Marwaha, \& Chaganti, 2011, p. 201).

\section{References}

Cleary, T. F. (1993). The flower ornament scripture. Boston, MA: Shambhala.

Harary, K., \& Targ, R. (1985). A new approach to forecasting commodity futures. PSI Research, 4, 79-85.

Hearst, P. C. (1982). Every secret thing. Garden City, NY: Doubleday.

Honorton, C., \& Ferrari, D. C. (1989). “Future telling”: A meta-analysis of forced choice precognition experiments, 1935-1987. Journal of Parapsychology, 53(4), 281-308.

Honorton, C., Berger, R. E., Varvoglis, M. P., Quant, M., Derr, P., Schechter, E. I., \& Ferrari, D. C., (1990). Psi communication in the Ganzfield: Experiments with an automated testing system and a comparison with a meta-analysis of earlier studies. Journal of Parapsychology, 54(2), 99-139.

Humphrey, B. S., Trask, V. V., May, E. C., \& Thomson, M. J. (1986). Remote viewing evaluation techniques. In E. C. May, \& S. B. Marwaha (Eds.), The Star Gate Archives: Reports of the 
United States Government sponsored psi program, 1972-1995, Volume 2: Remote viewing, 1985-1995. Jefferson, NC: McFarland.

Jaynes, J. (1976). The origin of consciousness in the breakdown of the bicameral mind. Boston: Houghton Mifflin.

Karma-glinpa, \& Reynolds, J. M. (2010). Self-liberation: Through seeing with naked awareness. An introduction to the nature of one's own mind from the profound teaching of selfliberation in the primordial state of the peaceful and wrathful deities; a terma text of Guru Padmasambhava expounding the view of Dzogchen; rediscovered by Rigdzin Karma Lingpa. Ithaca, N.Y: Snow Lion.

Larson, E. (1984, October 22). Did psychic powers give firm a killing in the silver market? The Wall Street Journal.

May, E. C., Lantz, N. D., \& Piantineda, T. (1996/2014). Feedback considerations in anomalous cognition experiments. In E. C. May, \& S. B. Marwaha (Eds.), Anomalous cognition: Remote viewing research and theory (pp. 104-116). Jefferson, NC: McFarland.

May, E. C., \& Marwaha, S. B. (Eds.). (2018a). The Star Gate Archives: Reports of the United States Government sponsored psi program, 1972-1995, Volume 1: Remote viewing, 1972-1984. Jefferson, NC: McFarland.

May, E. C., \& Marwaha, S. B. (Eds.). (2018b). The Star Gate Archives: Reports of the United States Government sponsored psi program, 1972-1995, Volume 2: Remote viewing, 1985-1995. Jefferson, NC: McFarland.

May, E. C., \& Marwaha, S. B. (Eds.). (2019a). The Star Gate Archives: Reports of the United States Government sponsored psi program, 1972-1995, Volume 3: Psychokinesis. Jefferson, NC: McFarland.

May, E. C., \& Marwaha, S. B. (Eds.). (2019b). The Star Gate Archives: Reports of the United States Government sponsored psi program, 1972-1995, Volume 4: Operational remote viewing: Memorandums and reports. Jefferson, NC: McFarland.

May, E. C., Marwaha, S. B., \& Chaganti, V. (2011). Anomalous cognition: Two protocols for data collection and analyses. Journal of the Society for Psychical Research, 75(905), 191-210.

May, E. C., Utts, J. M., Trask, V. V., Luke, W. W., Frivold, T. J., \& Humphrey, B. S. (1989). Review of the psychoenergetic research conducted at SRI International (1973-1988) (pp. 494-504). In In E. C. May, \& S. B. Marwaha (Eds.), (2018a), The Star Gate Archives: Reports of the United States Government sponsored psi program, 1972-1995, Volume 1: Remote viewing, 1972 1984. Jefferson, NC: McFarland.

Puthoff, H. E., \& Targ, R. (1973). Perceptual augmentation techniques, I (Executive Summary) (pp. 91-95). In E. C. May, \& S. B. Marwaha (Eds.), (2018a), The Star Gate Archives: Reports of the United States Government sponsored psi program, 1972-1995, Volume 1: Remote viewing, 1972-1984. Jefferson, NC: McFarland.

Puthoff, H. E., \& Targ, R. (1976). A perceptual channel for information transfer over kilometer distances: Historical perspective and recent research. Proceedings of the IEEE, 64(3), 329-354.

Puthoff, H. E., Targ, R., \& May, E. C. (1979). Standard remote viewing (RV) procedures: Local sites (pp. 243-247). In E. C. May, \& S. B. Marwaha (Eds.), (2018a), The Star Gate Archives: Reports of the United States government sponsored psi program, 1972-1995, Volume 1: Remote viewing, 1972-1984. Jefferson, NC: McFarland.

Schmeidler, G. (1964). An experiment on precognitive clairvoyance: Part 1. The main results. Journal of Parapsychology, 28(1), 1-14.

Schrödinger, E. (1964). My view of the world. Woodbridge, CT: Ox Bow Press.

Taimni, I. K., \& Patañjali. (2010). The science of yoga: The Yoga-sutras of Patañjali in Sanskrit with transliteration in Roman, translation in English and commentary. Wheaton, IL: Quest Books.

Targ, R. (2012). The reality of ESP: A physicist's proof of psychic abilities. Wheaton, Illinois: Quest Books. 
Targ, R. (2014). Special Orientation Techniques (U). Mindfield Bulletin, 7(1), 20-24.

Targ, R., Cole, P., \& Puthoff, H. E. (1974). Development of techniques to enhance man/machine. In E. C. May, \& S. B. Marwaha (Eds.), (2018a), The Star Gate Archives: Reports of the United States Government sponsored psi program, 1972-1995, Volume 1: Remote viewing, 19721984. Jefferson, NC: McFarland.

Targ, R., \& Puthoff, H. (1974). Information transmission under conditions of sensory shielding. Nature, 251(5476), 602-607. doi:10.1038/251602a0

Targ, R., Puthoff, H. E., Humphrey, B. S., \& May, E. C. (1980). Special orientation techniques (pp. 256-281). In E. C. May, \& S. B. Marwaha (Eds.), (2018a), The Star Gate Archives: Reports of the United States Government sponsored psi program, 1972-1995, Volume 1: Remote viewing, 1972-1984. Jefferson, NC: McFarland.

Targ, E., Targ, R., \& Lichtarge, O. (1985). Realtime clairvoyance: A study of remote viewing without feedback. Journal of the American Society for Psychical Research, 79(4), 493-500.

Targ, R., \& Tart, C. T. (1985). Pure clairvoyance and the necessity of feedback. Journal of the American Society for Psychical Research, 79(4), 485-492.

Warcollier, R., \& Schwartz, E. K. (1948). Mind to mind. New York: Creative Age.

Wargo, E. (2018). Time loops: Precognition, retrocausation, and the unconscious. San Antonio: Anomalist Books. 